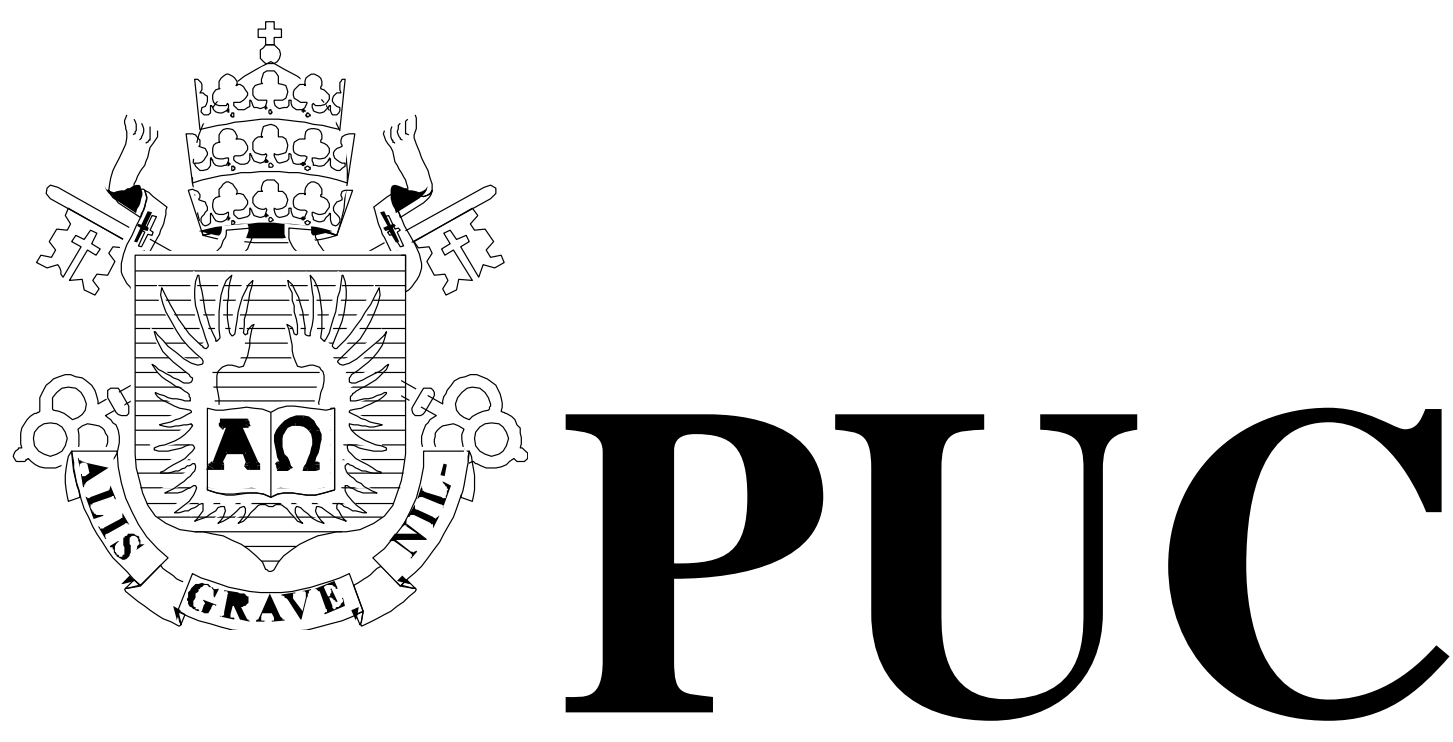

ISSN 0103-9741

Monografias em Ciência da Computação

$n^{\circ} 10 / 12$

Produção e Pesquisa Aliadas na Reestruturação do Ambiente Escolar

Mônica Costa Bruno Feijó

Andréia Resende

Mônica Couto

PONTIFÍCIA UNIVERSIDADE CATÓLICA DO RIO DE JANEIRO

RUA MARQUÊS DE SÃO VICENTE, 225 - CEP 22451-900

RIO DE JANEIRO - BRASIL 


\title{
Produção e Pesquisa Aliadas na Reestruturação do Ambiente Escolar
}

\author{
Mônica Costa*, Bruno Feijó*, Andréia Resende ${ }^{\star *}$, Mônica Couto*** \\ monica@inf.puc-rio.br, bfeijo@inf.puc-rio.br, andreiaresende@gmail.com, \\ monicacouto@uol.com.br
}

\begin{abstract}
This paper proposes a new model of school where a research center and a production center live in a symbiotic manner. Teaching/learning processes take place in the larger context of production activities, while research activities, besides establishing the grounds for pedagogical practices, give support to production. Firstly, some aspects of Brazilian education that reveal the need for structural changes in the traditional school model are pointed out. This changes are imperative if we are to keep this subsystem of society up with the contemporary world. The proposed model is then presented, followed by some examples of its application in the multimedia path of a technical high school.
\end{abstract}

Keywords: Projects in education; teacher research; interdisciplinary teaching; conceptual knowledge, skills, attitudes; curriculum organization.

Resumo. Este artigo propõe um novo modelo de escola onde um centro de pesquisa e um centro de produção convivem em simbiose. Os processos de ensino/aprendizagem acontecem no contexto maior das atividades produtivas, enquanto que as atividades de pesquisa, além de fundamentar as práticas pedagógicas, dão suporte à produção. Inicialmente, apontam-se aspectos da educação brasileira que evidenciam a necessidade de mudanças estruturais no modelo de escola tradicional que conhecemos, para que esse subsistema da sociedade esteja em sintonia com o mundo contemporâneo. Apresentase então o modelo proposto e alguns exemplos de sua aplicação em um curso de formação profissional na área de multimídia de uma escola de Ensino Médio Integrado.

Palavras-chave: Projetos na educação; professor pesquisador; interdisciplinaridade; conteúdos conceituais, procedimentais e atitudinais; organização curricular.

\footnotetext{
* VisionLab, Departamento de Informática PUC-Rio.

** Escola de Comunicação, UFRJ.

*** Pesquisadora Visitante, VisionLab, Departamento de Informática PUC-Rio.
} 


\section{In charge of publications}

Rosane Teles Lins Castilho

Assessoria de Biblioteca, Documentação e Informação

PUC-Rio Departamento de Informática

Rua Marquês de São Vicente, 225 - Gávea

22451-900 Rio de Janeiro RJ Brasil

Tel. +55 21 3527-1516 Fax: +55 21 3527-1530

E-mail: bib-di@inf.puc-rio.br 


\section{Introdução}

"Professor, essa conta aqui em Informática se faz do mesmo jeito que em Matemática?" Essa pergunta, feita por um aluno da primeira série do ensino médio em uma escola pública do Rio de Janeiro, é reveladora no que diz respeito à qualidade da educação brasileira. Os jovens, mesmo quando proficientes em repetir processos tais quais os envolvidos nas operações matemáticas elementares, não têm nenhuma ideia da origem destes processos e não fazem nenhuma conexão entre eles e o mundo em que vivem. Para eles, contas são coisas que se aprendem na escola, ou mais precisamente, em uma determinada disciplina, e servem para se conquistar alguns pontos nas avaliações daquela disciplina. Em paralelo a essa realidade, ao consultarmos os textos oficiais sobre o sistema educacional brasileiro, podemos verificar a alta qualidade destes textos e sua sintonia com as diretrizes apresentadas no relatório da Comissão Internacional sobre Educação para o Século XXI, elaborado para a UNESCO, sob a coordenação de Jacques Delors (Delors, 2012). Exemplo disso é o trecho retirado do texto de apresentação das Bases Legais dos Parâmetros Curriculares Nacionais para o Ensino Médio (Brasil, 2000):

\begin{abstract}
Partindo de princípios definidos na LDB, o Ministério da Educação, num trabalho conjunto com educadores de todo o País, chegou a um novo perfil para o currículo, apoiado em competências básicas para a inserção de nossos jovens na vida adulta. Tínhamos um ensino descontextualizado, compartimentalizado e baseado no acúmulo de informações. Ao contrário disso, buscamos dar significado ao conhecimento escolar, mediante a contextualização; evitar a compartimentalização, mediante a interdisciplinaridade; $e$ incentivar o raciocínio e a capacidade de aprender.
\end{abstract}

A pergunta do jovem diante de uma conta elementar é evidência de que o que acontece de fato na escola falha em dar significado ao conhecimento escolar, falha em evitar a compartimentalização e falha em incentivar o raciocínio. Onde é que se cria essa enorme lacuna entre o que se prevê na lei e nos textos oficiais e o que de fato acontece? Será que o conceito de competências é bem compreendido por todos os ato- res no cenário da educação? Será que está claro para todos que não basta dar nova roupagem aos conteúdos, parindo competências que servem para o preenchimento de colunas específicas em documentos padrão de planejamento, sem que se vislumbrem metodologias capazes de realmente levar os educandos ao desenvolvimento dessas competências? Será que os próprios educadores têm as competências básicas necessárias para conduzir os jovens à inserção na vida adulta com a formação prescrita nos documentos oficiais? Quais são essas competências? Será que os próprios educadores são capazes de realizar articulações entre os conhecimentos de diversas disciplinas, indo além da pluridisciplinaridade e percebendo a interdisciplinaridade (Roegiers \& De Ketele, 2004, p. 71)? Será que os próprios educadores praticam o "aprender a conhecer" e acompanham as mudanças de um mundo cada vez mais complexo e dinâmico, em um tempo em cuja importância do conhecimento é tão central que este termo foi utilizado para batizar a era em que vivemos - a "Era do Conhecimento"? Será que os próprios educadores, assim como se espera dos educandos, estão permanentemente "em estado de estudo" (Prado, 2011, p. 6)? Será que os próprios educadores praticam o "aprender a fazer" e se apropriam de novos fazeres fundamentais para a sua atuação em um mundo em que novas ferramentas e processos tornam-se velhos e ultrapassados em intervalos de tempo cada vez mais curtos? Será que gestores e educadores compreendem que a incorporação do "aprender a conviver" e do "aprender a ser" no processo formativo dos jovens não pode depender apenas de circunstâncias aleatórias?

Em matéria publicada em abril de 2011 pela revista Exame (Salomão \& Gianini, 2011), relata-se que, então, o país tinha cerca de 8 milhões de desempregados. Tal publicação se dá em um momento em que muito tem se falado no Brasil sobre um fenômeno batizado de "apagão de mão de obra", que se configura como a falta de mão de obra qualificada para ocupar determinados postos de trabalho. $\mathrm{O}$ aparente paradoxo reside no fato de que as vagas disponíveis exigem níveis de qualificação não atendidos por essa significativa legião de pessoas à margem da economia do país. Essa é mais uma evidência de que a escola não tem sido planamente 
eficaz em formar jovens para atuar no mundo contemporâneo. Prado (2011, p. 4) afirma que este não é um problema conjuntural, mas um problema estrutural. Acontece que a "Era do Conhecimento" exige dos profissionais perfil bastante diferente do que exigia a sua antecessora "Era Industrial". Hoje, um profissional que saiba apenas atuar executando tarefas de forma mecanizada já não tem facilidade de encontrar espaço no mercado de trabalho. Empregabilidade nos dias atuais implica em flexibilidade e multiespecialidade. Tecnologias se tornam obsoletas cada vez mais rapidamente. Adaptabilidade é palavra de ordem. O tradicional emprego vem cedendo espaço a ocupações temporárias sem vínculos contratuais. Como é que a escola vem de fato se posicionando diante deste cenário para garantir que as demandas do mundo do trabalho e, de forma mais abrangente, da vida na sociedade contemporânea, sejam de fato supridas por esta instituição a quem tradicionalmente sempre se conferiu este papel? Será que está claro para todos os atores no cenário da educação brasileira que modernizar a escola não pode ser apenas transformar o "quadro negro" na lousa digital? Será que está claro para todos que a modernização não se faz trazendo a vídeo-aula para a sala de aula? Aliás, será que ainda faz sentido o termo "sala de aula" em um tempo em que o educando carrega boa parte do conhecimento do mundo em seu telefone celular? Será que está claro para todos que não basta distribuir tablets para professores e alunos, já que boa parte dos professores não saberá utilizá-los, enquanto que os alunos não se beneficiarão deles sem que haja uma proposta pedagógica consistente para sua utilização?

Pestalozzi e Fröebel, ainda no século XVIII; Montessori, Decroly, Ferrière, Makarenko e Freinet, desde o início do século XX, sugerem mudanças significativas das práticas pedagógicas que culminam em um movimento que se convencionou chamar de "Escola Nova", também conhecido como "Escola Ativa" ou "Escola Progressiva". Dewey e seu aluno Kilpatrick se consolidam como dois nomes de vital importância para este movimento. No Brasil, a partir da década de 1930, Anísio Teixeira, Lourenço Filho, Fernando Azevedo dentre outros lideram o movimento da "Escola Nova". Quase um século já se passou. Por que é que estas e tantas outras ideias já não tão novas e tão difundidas entre estudiosos da educação até agora não foram capazes de promover mudanças expressivas na velha escola? Por que é que, ao contrário do que acontece em outras áreas da ciência, os avanços teóricos em educação não são incorporados pela sociedade de forma massiva?

Partindo do pressuposto de que a escola continua sendo uma instituição fundamental para a construção de uma sociedade democrática (Dewey, 1959), o presente artigo alerta para a urgência de mudanças da escola como a conhecemos tradicionalmente, e defende que estas mudanças devem ser estruturais. Inspirando-se em vários pensadores da educação, os autores propõem um modelo de escola cuja viabilidade e adequação às demandas da sociedade contemporânea vêm sendo testadas em um curso de formação profissional, o Curso Técnico de Multimídia, de uma escola de Ensino Médio Integrado. Os autores, entretanto, defendem a ideia de que o modelo proposto pode ser aplicado a escolas em qualquer nível de ensino.

\section{O Modelo}

Prado (2011) recorre à Teoria Geral dos Sistemas (TGS) para evidenciar a complexidade do sistema escolar e situá-lo como um subsistema de um sistema maior, a sociedade. Mais ainda, aquele autor chama a atenção para a necessidade de se enxergar a escola como um sistema aberto, em interação permanente com os demais subsistemas da sociedade, mantendo com eles fluxo constante na troca de informações, e, em função disso, sofrendo mudanças. Em particular, o autor explicita as relações do sistema escolar com o sistema produtivo, e alerta para o risco de colapso de um sistema que se isole.

Os textos oficiais que versam sobre o sistema educacional brasileiro mostram-se alinhados com essas ideias. Entretanto, pouco se evoluiu no sentido de trazê-las de fato para a realidade das escolas. Um exemplo disso é a reorganização do currículo por competências. Ao se apoiar em competências, ou seja, ao considerar o conhecimento de forma contextualizada, o conhecimento em ação, a escola busca trazer para dentro dela o cenário do sistema produtivo. Acontece que, raramente, equipe pedagógica e professores colocam em ação os conhecimentos que abordam na escola. Professores de Física 
são formados para "ensinar" Física e não para utilizá-la em situações de produção. Professores de Matemática são formados para "ensinar" Matemática e não para mostrar a sua aplicabilidade às mais diversas áreas do mundo produtivo. Professores e equipe pedagógica têm dificuldade de vislumbrar situações de mundo significativas que promovam a contextualização e a ótica interdisciplinar, pois jamais viveram estas situações.
Outro exemplo da sensibilidade dos textos oficiais ao papel da escola na formação do jovem para o contexto da sociedade atual é a preocupação em prepará-lo para lidar com o dinamismo do mundo contemporâneo, educandolhe para a busca permanente de conhecimento. Mais uma vez, entretanto, tal ideal é difícil de ser perseguido ao se considerar o modelo tradicional de escola, onde o próprio professor não é preparado e incentivado a manter-se em permanente estado de estudo.

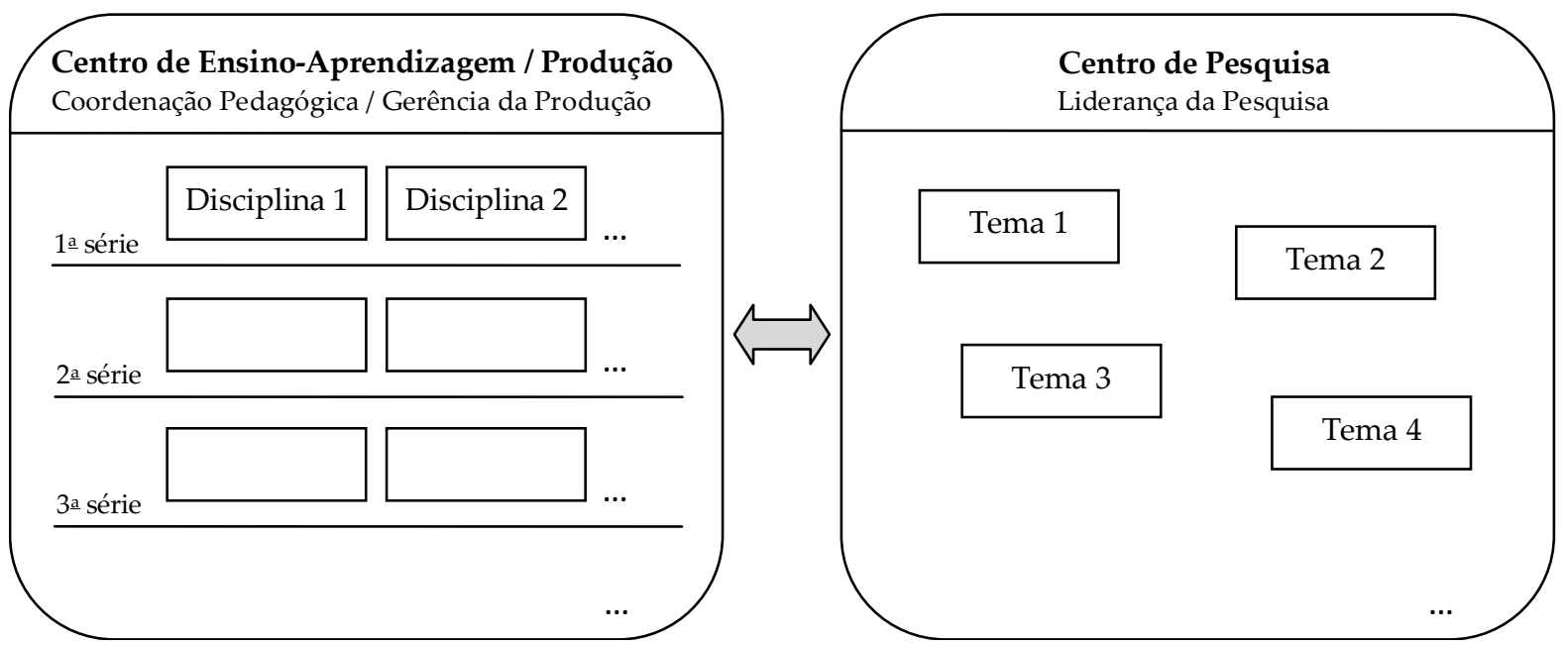

Figura 1: Centro de Produção e Centro de Pesquisa: as novas faces da escola no mundo contemporâneo.

Em face de constatações como estas, o presente trabalho propõe um modelo de escola que efetivamente traz para dentro de si o sistema produtivo, bem como permite que a escola mantenha troca constante de informações com os demais subsistemas da sociedade, através de atividades de pesquisa. Vale dizer que o modelo proposto não negligencia a realidade do país, e, embora proponha mudanças estruturais do sistema escolar, esta proposta é construída a partir de suas bases atuais. A Figura 1 dá destaque a duas novas faces da escola neste modelo, onde os processos de ensino/aprendizagem acontecem no contexto maior de um sistema de produção. A escola funciona também como um grande laboratório e atividades de pesquisa são motivadas não apenas por questões inerentes aos processos de ensino/aprendizagem, mas também por demandas geradas pela produção. Seus resultados são aplicados na própria escola. As demais seções deste artigo destinam-se a detalhar os vários aspectos da escola neste modelo.

\section{A Escola como Centro de Pro- dução}

\subsection{Organização Curricular}

Inspirando-se no que Zabala (1998) descreve como "métodos globalizados de organização dos conteúdos", propõe-se que o currículo seja concebido de forma orgânica, não apenas sobrepondo-se à organização por disciplinas, mas também rompendo as próprias fronteiras entre séries. Por questões de ordem prática, a estrutura de disciplinas deve ser mantida, já que ela facilita a gestão. Porém, o principal critério norteador do arranjo dos conteúdos deve ser a aprendizagem dos alunos, que deve se dar através de sua participação em projetos interdisciplinares.

Ao elencarem-se os conteúdos a serem abordados, propõe-se fazê-lo em conformidade à classificação proposta por Coll (1986), que organiza os conteúdos em três grandes grupos, a saber: conteúdos conceituais ("saber"), conteúdos procedimentais ("saber fazer") e conteúdos 
atitudinais ("ser"). Os conteúdos conceituais compreendem os princípios, as teorias, ideias e abstrações que fundamentam as práticas em qualquer área do conhecimento. $\mathrm{O}$ foco em conceitos visa a estimular nos jovens atitude crítica e reflexiva diante do mundo, em busca da essência das coisas. O como fazer nunca deve estar dissociado de seus porquês. Uma base conceitual consistente é condição primordial para fomentar nos jovens autonomia intelectual e capacidade de utilizar os conhecimentos adquiridos em situações inéditas para eles.

Já os conteúdos procedimentais, segundo Zabala (1999, p. 10), podem ser definidos como:

Um conteúdo procedimental - que inclui entre outras coisas as regras, as técnicas, os métodos, as destrezas ou habilidades, as estratégias, os procedimentos - é um conjunto de ações ordenadas $e$ com finalidade, quer dizer, dirigidas à realização de um objetivo.

Não obstante a importância de todo tipo de conhecimento que se convencionou aglutinar no termo "conteúdos conceituais", a vida requer também a prática, ou seja, a escolha de ferramentas e ações determinadas cuja execução ordenada leve à realização de uma ideia. Um currículo que coordene conteúdos conceituais e procedimentais contribui para formar jovens capazes de se adaptar, com um mínimo de esforço, às rápidas mudanças que caracterizam o cenário da tecnologia no mundo contemporâneo.

Quanto aos conteúdos atitudinais, Zabala (1998) afirma que eles envolvem valores, atitudes propriamente ditas e normas, e conceitua cada um destes grupos. Barnabé Saraiba (Coll et al., 1998) aborda a "aprendizagem e o ensino das atitudes". No contexto do presente trabalho, compreende-se por "atitude" a coerência na ação diante de determinado objeto. As atitudes envolvem os aspectos da formação dos jovens concernentes à sua relação consigo mesmo, com o outro, com a sociedade, com o ambiente, com o trabalho e com o conhecimento. Exemplos de atitudes que devem ser estimuladas nos educandos são a autoestima, a curiosidade, a criticidade, a autonomia, a responsabilidade, a iniciativa, a organização, o respeito aos outros e ao ambiente, a solidariedade e o comprometimento.
Vale salientar que o foco em conteúdos conceituais, procedimentais e atitudinais não deve limitar-se à elaboração do currículo. Ele deve permear todas as ações envolvidas no processo de ensino/aprendizagem, tais como o planejamento das propostas de trabalho e sua execução, e a elaboração dos instrumentos de avaliação. Ressalta-se também que, embora por questões de clareza e organização se faça distinção entre estes três grupos de conteúdos, eles devem ser encarados como indissociáveis em qualquer proposta de ação junto aos educandos. Esta constatação é uma das justificativas para a adoção de projetos como cerne da metodologia no modelo proposto.

Ainda sobre o processo de organização curricular, é importante destacar que ele não pode ficar exclusivamente a cargo dos professores. É vital a presença de um articulador pedagógico que tenha pelo menos visão geral das várias áreas de conhecimento e que seja capaz de articular conteúdos, observando critérios que promovam a interdisciplinaridade. Tal figura deve ser capaz não apenas de motivar a discussão, mas, principalmente, de orquestrar a atuação dos professores durante os trabalhos de elaboração do currículo. O caminho para que se chegue a um resultado final de qualidade deve ser cuidadosamente traçado e este resultado deve ser frequentemente revisto e, caso necessário, ajustado. Várias dimensões devem ser consideradas ao se traçar este caminho, tais como disciplinas, áreas do conhecimento e séries. Reuniões entre professores de uma mesma disciplina, reuniões entre professores de disciplinas distintas de uma mesma área de conhecimento, reuniões entre professores de áreas de conhecimento distintas, reuniões entre professores de uma mesma série, reuniões entre professores de séries distintas, enfim, a forma como se conduz a equipe durante o processo de organização curricular deve ser fruto de reflexão e planejamento consciente e é determinante para o sucesso da empreitada.

A fim de exemplificar a abordagem descrita para a organização curricular, seguem algumas considerações acerca do Curso Técnico de Multimídia, que vem sendo utilizado para prática e refinamento do modelo proposto. A Figura 2 mostra as disciplinas do curso. Um exemplo da organização curricular suplantando a organização por disciplinas é o que acontece na primeira 
série do curso, onde, além dos conteúdos das disciplinas de Iniciação à Informática e Introdução às Mídias Digitais, os conteúdos da disciplina de Artes Visuais, que faz parte do núcleo comum do ensino médio, foram todos analisados, distribuídos e ordenados conjuntamente pela equipe de educadores de forma a ganharem sentido através dos três projetos realizados pelos educandos ao longo do ano letivo.

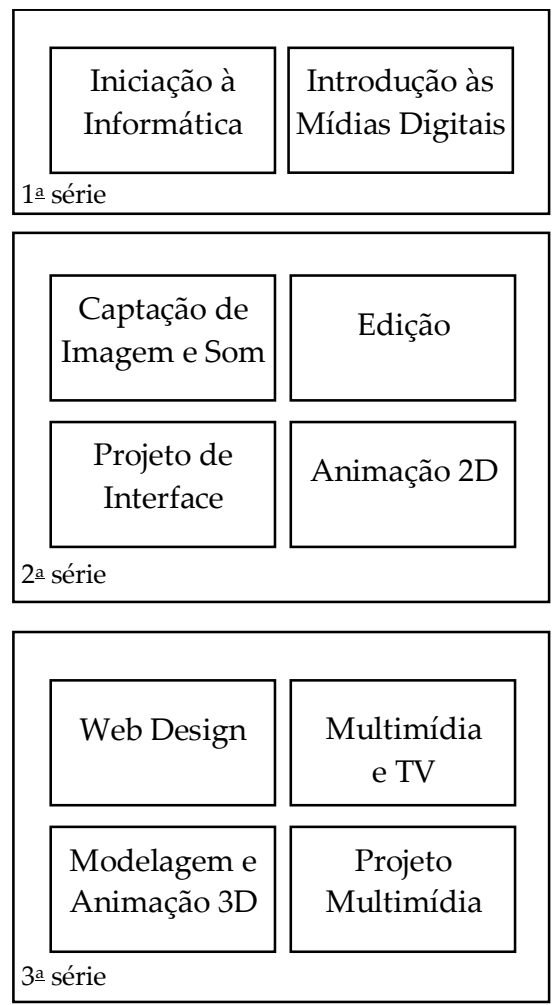

Figura 2: Organização do Curso Técnico de Multimídia em séries e disciplinas.

Outro exemplo onde se evidencia o caráter globalizador da organização curricular é o que acontece com as disciplinas de Captação de Imagem e Som e Edição. $\mathrm{O}$ avanço da tecnologia e a complexidade cada vez maior dos processos de produção tornam difícil o domínio por um mesmo profissional de todos os conceitos e técnicas envolvidos na produção audiovisual e, consequentemente, levam à especialização. Entretanto, é fundamental que os profissionais da área compreendam o processo de produção em sua totalidade. $\mathrm{O}$ particionamento dos saberes envolvidos neste processo não é inerente a ele próprio, e sim consequência do aumento de sua complexidade. Sobre os riscos da não articulação dos saberes fragmentados, Morin (1996, p. 20) alerta:
Entre todos esses fragmentos separados há uma zona enorme de desconhecimento e damo-nos conta de que o progresso dos conhecimentos constitui ao mesmo tempo um grande progresso do desconhecimento.

Refletindo a realidade para a qual se preparam os educandos, os currículos das disciplinas de Captação de Imagem e Som e Edição dialogam intimamente e os conhecimentos neles envolvidos articulam-se o tempo todo nos quatro projetos interdisciplinares que lhes dão sentido. Mais ainda, todos os conhecimentos adquiridos nestas duas disciplinas de segunda série são requisitados e se consolidam durante a realização de um projeto de terceira série, rompendo a fronteira entre estas duas séries.

$\mathrm{O}$ que acontece com as disciplinas de Introdução às Mídias Digitais, Projeto de Interface e Web Design é outro exemplo do rompimento das fronteiras entre séries. Estas disciplinas foram projetadas para que juntas dessem conta dos Princípios do Design e de sua aplicação no desenvolvimento de produtos para diferentes suportes. Conteúdos foram elencados e distribuídos cuidadosamente entre as disciplinas das três séries, eventualmente com repetições, para que, se engajando em projetos em diferentes contextos de aplicação, ao concluir o curso, o educando possua as competências e habilidades relativas ao Design previstas em seu perfil de saída.

\subsection{Projetos: O Cerne da Metodologia}

Na transição do século XIX para o século XX, iniciou-se entre pensadores da educação uma reação à educação tradicional e seus métodos baseados no instrucionismo e conteudismo descontextualizados, onde os educandos assumem papel secundário e passivo diante do professor, que é centro da dinâmica de ensino e detentor de todo o conhecimento. Este movimento, que no Brasil foi batizado de "Escola Nova", propunha a mudança do foco do ensino para a aprendizagem, do professor para o educando. Figura central para a "Escola Nova", Dewey (1959) analisa as relações entre a educação e uma sociedade verdadeiramente democrática, e defende a participação ativa do educando em seu processo formativo.

Esta proposta de mudança de postura da escola valorizava a cooperação, a relação horizontal 
entre alunos e professores, a experimentação e a pesquisa contribuindo para a aprendizagem significativa, a pluralidade de conhecimentos e o método científico concorrendo para a resolução de problemas de interesse dos alunos. Tudo isso com vistas a preparar o jovem para a vida em sociedade e, em particular, para o mundo do trabalho.

Embora a "Escola Nova", por fundamentar-se em determinados princípios, tenha entrado para a história da pedagogia como um movimento único, abordagens distintas foram propostas por vários pensadores. No que diz respeito à prática, diferentes expressões referem-se a formas de trabalho semelhantes, concebidas à luz daquele movimento: Metodologia de Projetos, Pedagogia de Projetos, Aprendizagem Baseada em Projetos (Project-Based Learning) e Aprendizagem Baseada em Problemas (Problem-Based Learning) são algumas delas. Todas elas derivam do "Método de Projetos" (The Project Method), proposto por Kilpatrick (1918). Um dos principais discípulos de John Dewey, em "Educação para uma sociedade em transformação", Kilpatrick (2011) apresenta a proposta conceitual de seu novo método.

Este artigo não pretende fazer uma revisão crítica dos princípios e práticas da "Escola Nova", nem discutir as particularidades de cada uma das propostas pedagógicas que nela se inspiraram. Nesta seção, apresentam-se as características de um projeto de acordo com o modelo presentemente proposto.

No contexto deste modelo, projetos são propostas de trabalho que simulam uma demanda do mundo real. Sua duração pode variar, mas, tipicamente, eles se estendem por, no mínimo, um bimestre letivo Todo projeto está associado a um produto a ser entregue pelos educandos ao final de sua execução, mas pode requerer também entregas intermediárias. Existem na literatura posições divergentes no que concerne à proposição dos projetos. Alguns defendem a ideia de que, para garantir o seu engajamento, a proposta deve partir necessariamente dos alunos. Outros acordam que os projetos devem ser propostos pelos professores. No modelo proposto, os projetos são a estratégia utilizada para que se articulem os conteúdos das diversas disciplinas dando-lhes sentido através da contextualização. Os conteúdos devem ser preferencialmente abordados em função das demandas que surgem durante a execução dos projetos. Como tal, para garantir que conteúdos previstos sejam de fato tratados, é importante que os projetos sejam definidos pela equipe pedagógica e professores. Entretanto, isso não exclui a possibilidade de interferência dos educandos em decisões de projeto. Algumas destas interferências podem ser previstas, já que os projetos podem ser concebidos com questões em aberto para discussão. Outras podem acontecer naturalmente como fruto do envolvimento dos educandos. É importante mencionar que, quanto mais aberto for um projeto às intervenções dos educandos, mais experientes e seguros devem ser os seus professores orientadores, já que o imprevisto certamente acontecerá com frequência.

No que diz respeito às disciplinas envolvidas, os projetos podem configurar-se de variadas formas. Eles podem envolver apenas uma (mesmo que envolvam conhecimentos de áreas distintas) ou várias disciplinas. Em uma escola profissionalizante na modalidade de Ensino Médio Integrado, por exemplo, os projetos podem envolver várias disciplinas de um mesmo curso, disciplinas de diferentes cursos, várias disciplinas do ensino médio regular, ou ainda disciplinas dos cursos técnicos integradas a disciplinas do ensino médio regular. Os projetos podem até mesmo envolver disciplinas de séries distintas, seja quando educandos de diferentes séries trabalham simultaneamente para sua realização, ou quando disciplinas de uma determinada série dão sequência a um projeto iniciado em série anterior.

A análise das várias possibilidades de integração entre disciplinas que se promovem através dos projetos está além dos objetivos deste trabalho. Roegiers \& De Ketele (2004) aprofundamse na questão da integração em suas várias formas.

Além dos projetos associados às disciplinas, a escola pode prever momentos de orientação, de engajamento voluntário, para os quais os educandos submetam suas propostas de projeto a serem avaliadas por um conjunto de professores, que atuarão como orientadores das propostas aprovadas.

Quanto à organização dos alunos, eles podem trabalhar individualmente, em duplas, ou em equipes maiores, dependendo das características e objetivos de cada etapa de um projeto. 
Quando organizados em equipes, normalmente, diferentes integrantes assumem funções distintas. Em alguns projetos é possível que um mesmo educando assuma papéis diversos em diferentes momentos da execução. A especificação de funções distintas acontece como forma organizar e viabilizar a produção, e respeita desejos e vocações dos alunos. Entretanto, é fundamental deixar claro que a responsabilidade pelo produto final é sempre de todos. Completar com sucesso as atividades associadas à sua função não exime os educandos de responsabilidade quanto ao sucesso do projeto como um todo. $\mathrm{O}$ incentivo à atitude colaborativa deve ser preocupação constante.

Prado (2011) faz uma extensa revisão das vantagens do trabalho com projetos na escola. Cabe ressaltar aqui que, além de promover a aprendizagem dos conteúdos conceituais e procedimentais através da contextualização, além de permitir que se rompam as fronteiras entre as várias áreas do conhecimento através da integração, os projetos criam ambiente favorável para que se trabalhem atitudes. Para que isso aconteça de forma efetiva, os conteúdos atitudinais devem ser foco de atenção desde a concepção do projeto até a sua finalização. A conceituação, a organização dos alunos, os produtos a serem gerados, as atividades planejadas, tudo isso deve levar em conta a dimensão atitudinal. A atuação dos orientadores não deve se restringir aos aspectos técnicos da produção, mas deve se ocupar também das questões atitudinais.

A seguir, apresentam-se exemplos de projetos conduzidos no Curso Técnico de Multimídia, relacionando-os a algumas considerações feitas acima.

A Figura 3 mostra ilustrações produzidas pelos educandos no contexto do Projeto Alice (2010), exemplo em que o envolvimento dos alunos alterou os rumos previstos pela equipe que o concebeu. Neste projeto, os alunos de segunda série do Curso Técnico de Multimídia desenvolveram toda a parte gráfica de um jogo para computador, incluindo sua identidade visual, os personagens, cenários, animações, e telas. $\mathrm{Na}$ proposta original, os professores previram a utilização de determinados recursos para a concepção visual do jogo. Entretanto, os alunos se posicionaram e defenderam uma proposta diferente, na qual eles criariam ilustrações. Diante de seus os argumentos qualificados, os rumos do projeto foram alterados.

Um bom exemplo das diferentes possibilidades de integração entre as disciplinas que participam de um projeto é a edição de 2011 do Projeto Porta-Retratos. Este projeto acontece anualmente envolvendo as disciplinas de Captação de Imagem e Som e Edição. Alguns de seus objetivos principais são: incitar a reflexão sobre as relações entre a fotografia e a imagem em movimento; estimular a compreensão do surgimento da imagem fotográfica como um acontecimento histórico, social, e político; abordar os fundamentos e os princípios da fotografia; abordar os fundamentos e os princípios da montagem cinematográfica; abordar técnicas de fotografia e de montagem. Para que se atinjam estes e outros objetivos, cada dupla de educandos recebe a encomenda de produção de um vídeo, composto por outros dois vídeos emoldurados. Cada um destes vídeos exibe a atuação de um dos componentes da dupla, representando algum personagem. Na composição dos vídeos individuais eles devem dialogar. A Figura 4 mostra um quadro do vídeo produzido por uma das duplas.

Este projeto é executado todos os anos, mas o briefing para a realização dos vídeos muda a cada edição. Em 2011, os vídeos trataram da contenda entre duas figuras importantes para a história da ciência - Newton e Leibniz - acerca da autoria do Cálculo. Além das disciplinas do curso técnico que constituem o "núcleo duro" do projeto, dessa edição participaram também as disciplinas de Filosofia, Física e Teatro. À Filosofia coube orientar o estudo do texto "Newton contra Leibniz: um Choque de Titãs" (Hellman, 1999), estimulando a compreensão do embate entre os pensadores, analisando e discutindo as posturas ética, política e pessoal de ambos. À Física possibilitou-se tratar de conteúdos da Mecânica Newtoniana aproximando-os da realidade dos educandos através da humanização do conhecimento científico. A disciplina de Teatro abordou técnicas de interpretação, possibilitando a sua prática através da orientação dos alunos "atores" diante da câmera. 


\section{alice tomn}
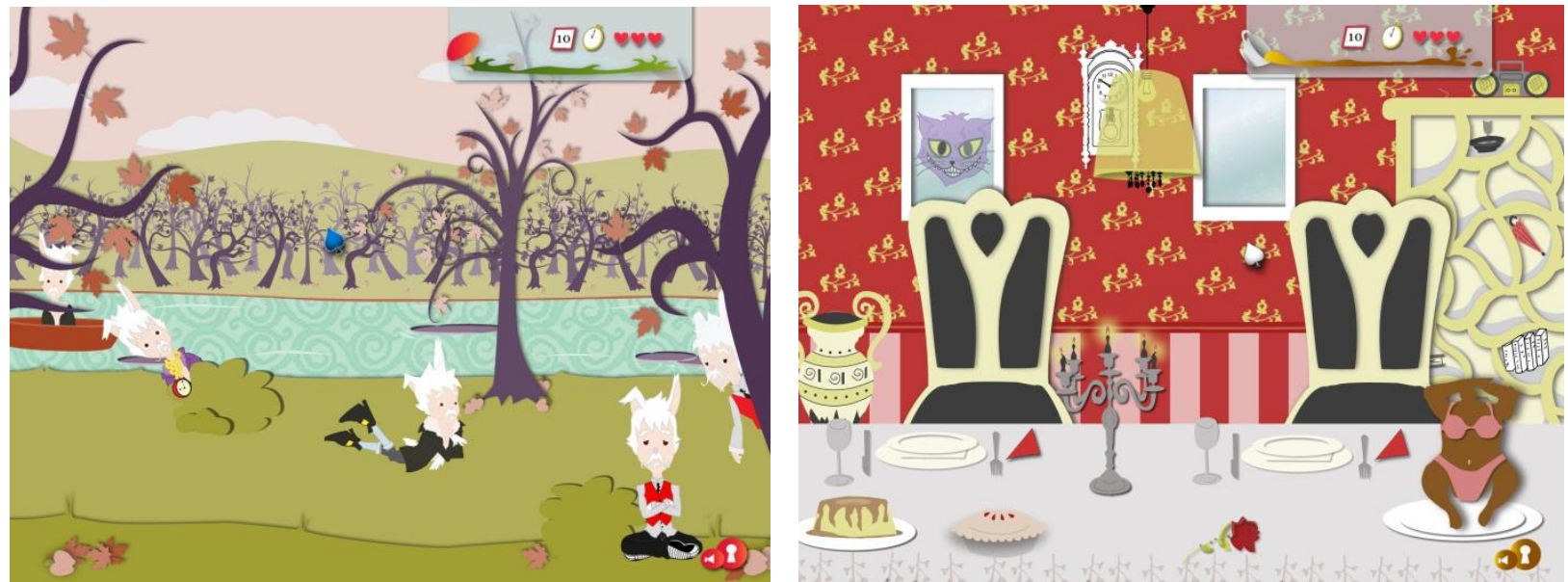

Figura 3: Imagens produzidas pelos educandos para o Projeto Alice, $2^{\mathrm{a}}$ série, 2010.

No exemplo do Projeto Porta-Retratos percebem-se diferentes formas de integração entre as disciplinas envolvidas. No que tange a Captação de Imagem e Som e Edição, a integração se dá de forma interdisciplinar, já que as contribuições de cada uma dessas disciplinas concorrem para a realização do projeto. A produção audiovisual a ser realizada funciona como sistema totalizador dos conceitos e técnicas abordados. O mesmo não acontece, por exemplo, no que diz respeito à integração destas disciplinas com a Física. Nesse caso, a integração se dá apenas pelo tema.

Um bom exemplo da pertinência da abordagem de projetos para a consideração de questões atitudinais é o projeto Engenhoca, que foi conduzido junto às turmas de segunda série do Curso Técnico de Multimídia no primeiro bimestre de 2012. Este projeto foi concebido com o objetivo principal de introduzir alguns princípios da animação tradicional que estabelecem aspectos da Física a serem observados ao se criar uma animação natural e convincente aos olhos do espectador. Para motivar a reflexão sobre os aspectos físicos do movimento e vislumbrar formas de retratá-los em uma animação, os alunos receberam a encomenda de produzir uma "engenhoca". Uma bolinha seria "solta" e percorreria engrenagens, planos inclinados e tubos, acionaria alavancas, quicaria em molas, até chegar a um ponto de parada. Cada uma das duas turmas projetaria a sua própria engenhoca. Dentro de cada turma, cada equipe de alunos projetaria e produziria uma parte do mecanismo. As partes individuais, entretanto, deveriam se unir em um único artefato. A produção seria toda feita com recortes de cartolina e fotos individuais do posicionamento manual da bolinha ao longo da engenhoca. A exibição das fotos a uma taxa apropriada produziria a animação desejada.

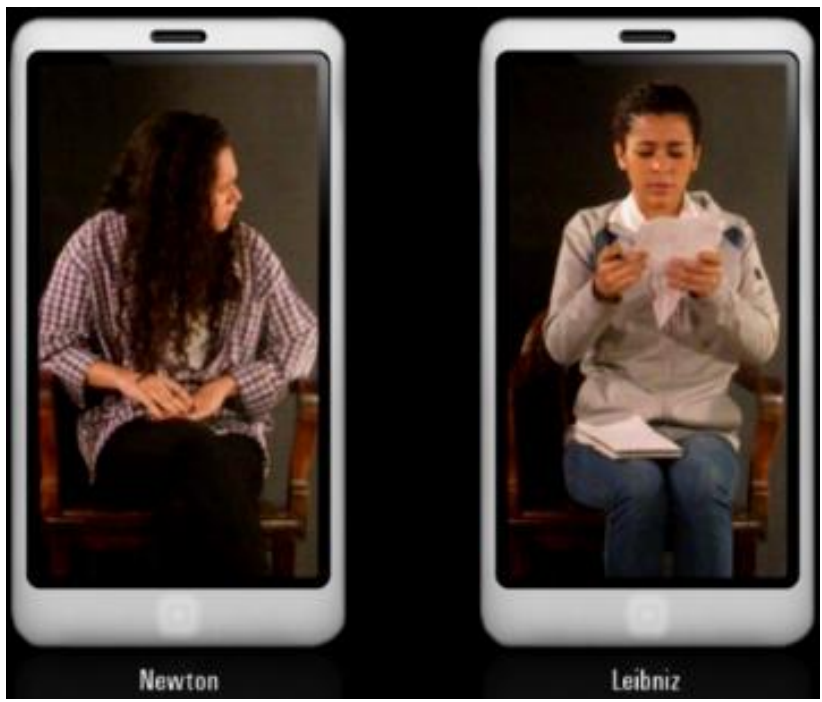

Figura 4: Quadro de vídeo produzido por uma dupla de alunos para o Projeto Porta-Retratos, 2011.

A execução deste projeto, além de atitudes trabalhadas em qualquer outro, tais como curiosidade, criticidade, autonomia, responsabilidade e comprometimento, criou um novo nível de interação no trabalho colaborativo, já que a colaboração se deu não apenas dentro de uma 
equipe, mas entre equipes, promovendo ainda mais atitudes tais como liderança, organização, respeito e solidariedade. Segundo relato dos alunos, este projeto foi importante para unir as turmas recém-formadas de segunda série e consolidá-las como grupos que se manterão juntos até o final do curso.

A mudança do ambiente escolar provocada pelo trabalho com projetos traz consigo desafios que põem à prova a estrutura tradicional da escola. A próxima seção trata desta questão.

\subsection{Desafios}

O trabalho com projetos muda o ambiente da escola que conhecemos. O papel do professor deixa de ser o de expositor e passa a ser o de orientador e consultor. A unidade de planejamento deixa de ser a aula e passa a ser o próprio projeto. Aliás, o termo "aula" perde sentido e dá lugar ao termo "encontro". Os encontros para produção são configurados de acordo com o andamento do projeto. Por exemplo, dependendo da fase em que se encontre, pode ser necessária a presença simultânea de consultores (professores) especialistas em diferentes áreas. $\mathrm{O}$ espaço onde se dão os encontros também é flexível, destituindo a "sala de aula" de seus privilégios. Múltiplos espaços podem ser ocupados simultaneamente por diferentes educandos dependendo de suas funções no projeto. Os documentos tradicionalmente utilizados já não dão conta do planejamento neste novo modelo. Modelos específicos precisam ser vislumbrados para documentação e registro dos projetos. As ferramentas tradicionalmente utilizadas por professores e alunos cedem lugar a novas ferramentas, tais como plataformas de trabalho colaborativo, redes sociais e ferramentas de trabalho em nuvem.

Todas essas mudanças impõem à escola novos requisitos que não se limitam ao âmbito pedagógico e que precisam ser bem compreendidos para que o novo modelo tenha sucesso. Uma das consequências imediatas da transformação da escola em centro de produção diz respeito ao novo perfil do professor para que ele atue como um líder de projetos. Essa função demanda competências específicas que não são trabalhadas nos atuais cursos de formação de professores. Nos cursos de formação profissional, a presença na escola de professores que também atuem no mercado pode ser vista como uma oportunidade de alavancar os outros membros da equipe, através das interações que se dão na condução de projetos integrados. Em escolas de outras modalidades, uma possível solução para o problema pode ser o estímulo à presença de profissionais de mercado aposentados que ora atuem como professores. Seja como for, é importante perceber que, para orquestrar a equipe de professores na condução dos projetos, surge a necessidade de um novo elemento no quadro de funções da escola: o gerente de produção. A este profissional, além de garantir que as demandas da produção sejam satisfeitas, cabe, por exemplo, orientar os professores na condução, documentação e registro dos projetos. Sua atuação deve ser dar em estreita parceria com a coordenação pedagógica.

As mudanças provocadas pelo trabalho com projetos causam impacto também sobre a gestão. No modelo proposto, a relação entre professores e alunos deixa de ser vertical. Professores, trabalhando em equipes, atuam como consultores, e alunos colaboram para a realização dos projetos. Essa horizontalização das relações, onde se valoriza o trabalho colaborativo e enfraquece-se a hierarquia é, na verdade, uma tendência exibida pelas corporações no mundo contemporâneo. Google e Dell são algumas referências no modelo de gestão descentralizada. Portanto, aproximar a escola de um moderno modelo de gestão corporativa é mais um atrativo da incorporação da prática de projetos. Mas a aproximação da escola do modelo de gestão descentralizada não deve se restringir ao aspecto pedagógico. A horizontalização das relações nas corporações, através da eliminação de níveis hierárquicos e da promoção do trabalho em equipes, é uma resposta à necessidade de agilidade para se lidar com o dinamismo do mundo atual, bem como uma forma de se estimular a criatividade em um cenário globalizado onde a inovação é premente. Além disso, um modelo de gestão que se apoia na confiança entre pares e não no controle sobre subordinados favorece um ambiente de trabalho onde prevalece o comprometimento e a ética. Todas essas considerações são indícios de que a escola como um todo pode se beneficiar da horizontalização. $\mathrm{O}$ trabalho com projetos é por si só inovador e exige agilidade. Para que se realize com sucesso e não seja ape- 
nas mais uma formalidade, é preciso que os professores sejam motivados e que tenham liberdade para dar vazão à sua criatividade. É desnecessário dizer que com o aumento da liberdade, aumenta também a responsabilidade de cada indivíduo.

É importante destacar que o modelo de gestão descentralizada pressupõe comunicação eficiente e livre circulação da informação. Assim como nas empresas, uma possível dificuldade para sua implantação nas escolas é fazer com que os atuais gestores compreendam que abrir mão de poder e de status em uma organização onde prevalece a parceria é um movimento em que todos podem ganhar.

No que diz respeito ao Curso Técnico de Multimídia, destaca-se que a descentralização tem se mostrado uma forte aliada da inovação. Não apenas professores são estimulados a participar ativamente da gestão do curso, como também os educandos. Em reuniões mensais com a gestão, eles manifestam apoio a algumas práticas, fazem críticas construtivas, propõem soluções, sugerem mudanças. Esse processo de construção coletiva não apenas fortalece o curso, como dá espaço aos jovens para exercitarem a democracia.

\section{A Escola como Centro de Pes- quisa}

A Figura 1 deste trabalho ilustra o modelo de escola proposto, destacando suas atividades de produção e de pesquisa. Assim como a condução de projetos como prática pedagógica impõe à escola novos requisitos, o mesmo acontece com relação às atividades de pesquisa. Mais uma vez, colocam-se imediatamente questões sobre o perfil dos professores.

Qual seria o perfil dos professores em um sistema educacional como o nosso, que pressupõe a "participação dos docentes na elaboração da proposta pedagógica dos estabelecimentos de ensino" (Brasil, 2006, p. 7)? Os textos oficiais que apontam os rumos a serem seguidos pela educação no país podem prover insights sobre o perfil que devem ter a equipe pedagógica e os professores de uma escola. Por exemplo, o texto das Orientações Curriculares Nacionais para o Ensino Médio (Brasil, 2006, p. 16), referindo-se às Diretrizes Curriculares Nacionais para o Ensino Médio de 1998 (Brasil, 1998) diz:
A implantação das DCNEM nas escolas, em seu projeto político-pedagógico, e pelo professor, na prática pedagógica em sala de aula, demandam acompanhamento, orientação e capacitação de gestores escolares e docentes. A implementação das DCNEM depende largamente de fomento $e$ apoio às escolas, notadamente por instituições responsáveis por cursos de formação de professores, o que ainda não se efetivou. Como resultado, constata-se o distanciamento entre esse documento e a realidade escolar.

\section{E segue...}

Com relação à Biologia, os PCNEM apresentam um diálogo que não aprofunda suficientemente suas principais questões junto aos professores; o texto perde-se em exercícios de reflexão que são pouco efetivos quando aplicados em sala de aula. Embora o documento traga orientações gerais sobre os princípios norteadores da prática didática, faltam, na verdade, sugestões e propostas ao professor do "como fazer".

Enquanto os textos acima denunciam o excesso de reflexão e reivindicam para os professores orientações e até mesmo a receita do "como fazer", estes mesmos textos pregam a formação de um jovem com "autonomia intelectual" e "pensamento crítico". Almeja-se a preparação dos jovens para aplicar os conhecimentos adquiridos na escola a situações de vida diversas, a situações novas com as quais não tenham se deparado durante sua vida escolar. Pretende-se formar jovens capazes de lidar com o dinamismo do mundo e de se autoavaliar constantemente para continuar autonomamente o seu aprendizado e buscar novos conhecimentos quando o repertório que possuem já não for suficiente para resolver problemas com os quais se deparem. Pretende-se formar jovens que rompam com o senso comum e compreendam o fazer científico. Pretende-se formar jovens que, quando expostos a novos problemas, sejam capazes de elaborar hipóteses e de construir modelos. Pretende-se formar jovens com atitude investigativa, jovens que não se contentem com fórmulas prontas (o "como fazer"), mas que busquem a sua origem e que saibam eles próprios vislumbrá-las.

Acerca da postura diante do ensino das ciências Miller (2000) afirma:

[...] sem os conhecimentos e habilidades necessárias para efetuar estes novos objetivos e estraté- 
gias, o professorado não será capaz de operar eficazmente nos cursos. Sua formação e capacitação devem ter a mesma base pedagógica que os estudantes, para uma compreensão ampla da ciência como empresa social e humana, e esta deve manter-se ao longo da carreira profissional.

Ora, se a escola pretende formar jovens com determinadas competências e habilidades, é razoável esperar que os guias na condução para esta formação tenham eles próprios estas competências e habilidades. Não deveria ser necessário, por exemplo, dizer aos professores o "como fazer". Os desafios pertinentes à educação para o século XXI deveriam ser suficientes para provocar-lhes o incômodo que culminaria na elaboração de hipóteses e na construção de modelos para a solução dos novos problemas.

Acontece que os professores de hoje não tiveram o tipo de formação que se espera prover aos jovens. Claro está que, para que se rompa o ciclo que perpetuará o modelo tradicional de educação, é preciso fazer algo para que os atuais educadores adquiram as mesmas competências e habilidades que devem ajudar a desenvolver nos educandos. Assim como a formação que se espera dos alunos não se dá no tempo de uma disciplina ou de uma série, mas ao longo de toda a sua trajetória formativa, não se pode esperar que capacitações pontuais formem o professor protagonista de um novo modelo de educação.

A solução para este aparente dilema, prevista no modelo que se propõe neste trabalho, é trazer a pesquisa para dentro da escola. Competências, habilidades e atitudes que se desejam promover entre os jovens, tais como atitude investigativa, estado de estudo permanente, posicionamento crítico diante do mundo, postura reflexiva, abordagem científica diante de problemas, elaboração de hipóteses e proposição de modelos, prática de registro e sistematização são inerentes à atividade de pesquisa acadêmica. Assim como a aproximação entre a indústria e a universidade é algo reconhecidamente desejável, e até mesmo incentivado por políticas públicas, como forma de acelerar a inovação de produtos e processos industriais, a sociedade pode também se beneficiar da aproximação entre a escola e a universidade com a aceleração da inovação dos processos educacionais. A incorporação da pesquisa dá uma nova face à escola, que deixa de se comprome- ter apenas com a transmissão de conhecimento e passa a ser um laboratório para a produção de conhecimento. Uma área de pesquisa necessariamente abraçada por estas escolas-laboratório deve ser a própria área de educação.

A presença na escola de profissionais com experiência na condução de pesquisa acadêmica e sua interação com outros educadores e com os próprios educandos pode potencializar o desenvolvimento de competências e habilidades desejáveis nestes atores do processo educativo. A convivência no próprio ambiente escolar e a colaboração entre sujeitos com conhecimentos diferentes deve promover a aprendizagem e se mostrar mais efetiva do que qualquer ação instrucionista dirigida à equipe pedagógica e aos professores.

O Curso Técnico de Multimídia, que vem sendo utilizado para que se testem as ideias propostas neste trabalho, é um exemplo desta prática. A organização e gestão do curso é fruto de parceria com uma universidade. À frente da coordenação pedagógica do curso tem-se um profissional com longa experiência em pesquisa acadêmica. Sua atuação se aproxima da de um líder de pesquisa e cada professor do curso, alguns deles também com experiência acadêmica, faz parte do time. Dentre as áreas investigadas pelos professores-pesquisadores incluemse: a escola no mundo contemporâneo, os projetos na educação, os modelos de integração, o uso das Tecnologias de Informação e Comunicação (TIC) na educação, a importância da alfabetização visual na sociedade contemporânea, dentre outras. O curso funciona como um grande laboratório onde qualquer prática é alvo de olhar reflexivo e onde registro e sistematização são palavras de ordem.

Lüdke (2001) afirma que, embora a ideia da pesquisa como componente necessário ao trabalho do professor seja reconhecida de maneira unânime e apareça nas obras de inúmeros autores, pouco se sabe sobre sua prática efetiva nas escolas brasileiras. Elliot (1991) apresenta a pesquisa-ação como uma forma de desenvolvimento profissional e analisa os potenciais benefícios desta prática tanto para os professores quanto para os acadêmicos. 


\section{Conclusão}

O modelo proposto traz para dentro da escola o sistema produtivo, bem como permite que ela esteja em permanente processo de revisão e atualização através de atividades de pesquisa. A aliança da produção e da pesquisa mudam o status da escola de reprodutora de conhecimento para produtora de conhecimento. Ciente de que a formação integral do jovem demanda competências não estimuladas pelos atuais cursos de formação de professores, para que se rompa o ciclo estabelecido, o presente trabalho propõe a promoção de um ambiente onde convivam profissionais com experiências distintas. Esta diversidade deve potencializar o desenvolvimento de toda a equipe.

$O$ presente modelo vem sendo testado com êxito em um curso de formação profissional na área de multimídia de uma escola na modalidade de Ensino Médio Integrado. Entretanto, os autores acreditam que ele se aplique a escolas de qualquer nível e modalidade.

\section{Agradecimentos}

Os autores agradecem ao Instituto Oi Futuro pela oportunidade de testar a teoria desenvolvida neste trabalho de pesquisa no Projeto NAVE, onde o VisionLab/PUC-Rio é responsável pela operação do Curso Técnico de Multimídia. Este trabalho é também parcialmente financiado pelo CNPq, FINEP, CAPES, VisionLab/PUC-Rio e Depto. de Informática/PUCRio.

\section{Referências}

BRASIL. Resolução no 3, de 26 de junho de 1998, da Câmara de Educação Básica do Conselho Nacional de Educação, que institui as Diretrizes Curriculares Nacionais para o Ensino Médio. Diário Oficial da União, Brasília, DF, p. 21, 05 de agosto. 1998. Seção 1.

BRASIL. Ministério da Educação, Secretaria de Educação Média e Tecnológica. Parâmetros Curriculares Nacionais para o Ensino Médio: Bases Legais. Brasília: MEC/Semtec, 2000.

BRASIL. Ministério da Educação, Secretaria de Educação Básica. Orientações Curriculares para o Ensino Médio. Brasília: MEC/SEB, 2006. v. 2.

COLL, C. Marc curricular per a l'ensenyament obligatori. Barcelona: Departament d'Ensenyament de la Generalitat de Catalunya, 1986.

COLL, C.; POZO, J. I.; SARABIA, B.; VALLS, E. Os conteúdos na reforma: ensino e aprendizagem de conceitos, procedimentos e atitudes. Porto Alegre: Artmed, 1998.

DELORS, J. (Coord.). Educação: um tesouro a descobrir: Relatório para a UNESCO da Comissão Internacional sobre Educação para o século XXI. 7. ed. São Paulo: Cortez, 2012.

DEWEY, J. Democracia e educação: introdução à filosofia da educação. 3. ed. Tradução Godofredo Rangel e Anísio Teixeira. São Paulo: Nacional, 1959.

ELLIOTT, J. Action research for educational change. Buckingham: Open University Press, 1991.

HELLMAN, H. Grandes debates da ciência: dez maiores contendas de todos os tempos. Tradução de José Oscar de Almeida Marques. São Paula: UNESP, 1999.

KILPATRICK, W. H. The Project Method. Teachers College Record, v. 19, n. 4, p. 319335, 1918.

KILPATRICK, W. H. Educação para uma sociedade em transformação. Petrópolis: Vozes, 2011.

LÜDKE, M. O professor e a pesquisa. Campinas: Papirus, 2001.

MORIN, Edgar. O problema epistemológico de complexidade. 2. ed. Lisboa: EuropaAmérica, 1996.

PRADO, F. L. Metodologia de Projetos. São Paulo: Saraiva, 2011.

ROEGIERS, X.; DE KETELE, J. M. Uma pedagogia da integração: competências e aquisições no ensino. 2. ed. Porto Alegre: Artmed, 2004.

SALOMÃO, A.; GIANINI, T. Um país em busca de gente para trabalhar. Exame, São Paulo, ano 45, no 6, 6 abr. 2011.

ZABALA, A. A prática educativa: como ensinar. Porto Alegre: Artmed, 1998.

ZABALA, A. (Org.). Como trabalhar os conteúdos procedimentais em aula. 2. ed. Porto Alegre: Artmed, 1999. 